\title{
Phagocytosis in normal and anaemic blood
}

\author{
ALLAN JACOBS \\ From the Department of Pathology, Welsh National School of Medicine, Cardiff
}

SYNOPSIS The phagocytic activity of neutrophil leucocytes in whole blood is increased in cases of iron-deficiency anaemia. It has been suggested that this is due to some intrinsic change in the leucocytes themselves as a result of anaemia. The present study, however, shows that an artificial reduction of the volume of red cells in normal blood leads to a similar increase in activity. There is no difference in phagocytosis by neutrophils from normal and anaemic blood when the volume of red cells is reduced to a uniformly low level in each case. It is suggested that the increased activity in anaemic blood is due to decreased mechanical interference between leucocytes and particles by the red cells.

An increase in the phagocytic activity of neutrophil leucocytes in blood from anaemic patients has been reported by Berry, Davis, and Spies (1945). Further work by Berry, Leyendecker, and Spies (1947) indicated that this was an intrinsic function of the leucocytes themselves and not dependent on changes in the red cells or serum. This observation is of interest since the tissues of anaemic patients or animals usually show signs of reduced activity or degenerative changes if they are affected at all. An attempt to define this increase in activity has been made and the results show only an apparent increase of neutrophil phagocytosis in anaemic blood due to a reduced red cell volume.

\section{METHODS}

Phagocytic activity was measured by the ability of leucocytes to ingest heat-killed organisms in a standardized suspension at $37^{\circ} \mathrm{C}$. The organism chosen for these experiments was Staph. aureus (National Collection of Type Cultures no. 6571). A 24-hour culture of this organism on plain agar was suspended in normal saline and placed in a water bath at $62^{\circ} \mathrm{C}$. for two hours. The dead organisms were then washed with saline and resuspended so as to give an optical density of 0.35 in a Spekker photoelectric colorimeter, using a Kodak no. 4 filter with maximum absorption at $520 \mathrm{~m} \mu$. Suspensions were kept at $4^{\circ} \mathrm{C}$. and were warmed to $37^{\circ} \mathrm{C}$. before each experiment. A new suspension was prepared each week. In each test 1 volume of heparinized blood, prepared as indicated in individual experiments, was well mixed with 1 volume of the warm bacterial suspension and part of the mixture was incubated at $37^{\circ} \mathrm{C}$. in a capillary tube sealed with plasticine for 20 minutes.

Received for publication 11 June 1963.
Films were made from the contents of the tube and stained by the Jenner-Giemsa method. The number of organisms ingested by 100 neutrophil polymorphs was counted. Under the conditions of the test this fell in the range 500 to 1,000 for normal blood, the variation being due to slight differences in bacterial concentration in each new suspension. The phagocytic index of each preparation is the number of organisms ingested by 100 neutrophil polymorphs expressed as a percentage of the mean value obtained from all the normal blood specimens incubated with the same suspension. The volume of packed red cells (V.P.R.C.) was measured by using the Hawksley micro-haematocrit centrifuge at $12,000 \mathrm{~g}$ for five minutes.

The anaemic patients studied were all suffering from marked iron-deficiency anaemia, due in most cases to chronic blood loss. Following the investigation they all responded completely to iron therapy and the peripheral blood picture returned to normal. The normal subjects were all healthy members of the hospital and laboratory staff.

\section{RESULTS}

Neutrophil phagocytic activity varies somewhat between different normal individuals, but remains fairly constant for any one subject. For this reason, normal blood specimens in each experiment were obtained from different subjects whenever possible.

The leucocyte counts of all blood specimens were within normal limits (Dacie, 1956) and phagocytic activity was not related to leucocyte concentration in this range. The incubation of all blood-bacterial mixtures was started within 10 minutes of blood being taken, and in the case of capillary blood within two minutes. It was shown that if blood was left standing at room temperature for $\mathbf{4 0}$ minutes 


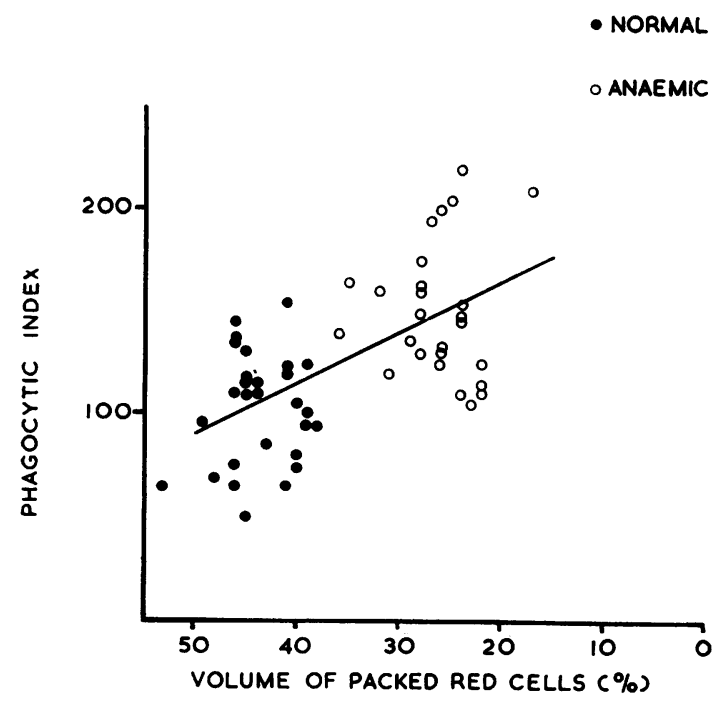

FIG. 1. The phagocytic index of whole blood in normal and anaemic subjects related to the volume of packed red cells.

before incubation then there was a reduction in the phagocytic index.

EXPERIMENT 1 Phagocytosis was measured in 60 specimens of normal blood. The mean phagocytic index was $101.8 \pm 7 \cdot 3$. The mean phagocytic index in 28 specimens of blood from patients suffering from iron-deficiency anaemia was $154.5 \pm 6.0$. The observed difference is highly significant $(\mathrm{p}=$ $<0.00001)$. Figure 1 shows the phagocytic index of 28 specimens of normal and 26 specimens of anaemic blood plotted against the volume of packed red cells in these specimens. A low volume of packed red cells is associated with a high phagocytic index but this could be due to an intrinsic difference between the normal and anaemic leucocytes or plasma.

EXPERIMENT 2 Duplicate venous specimens of blood were obtained as indicated from 18 normal subjects. Some of the red cells were removed from one of the specimens in each case. The mean normal phagocytic index was calculated from the specimens from which no red cells were removed. In all cases removal of red cells resulted in an apparently higher phagocytic activity of the neutrophils. Figure 2 shows the relation between the phagocytic index and the volume of packed red cells in normal blood. It may be concluded that an increased phagocytic index can be due to simple mechanical lowering of the volume of packed red cells without any change in the nature of the leucocyte or plasma.

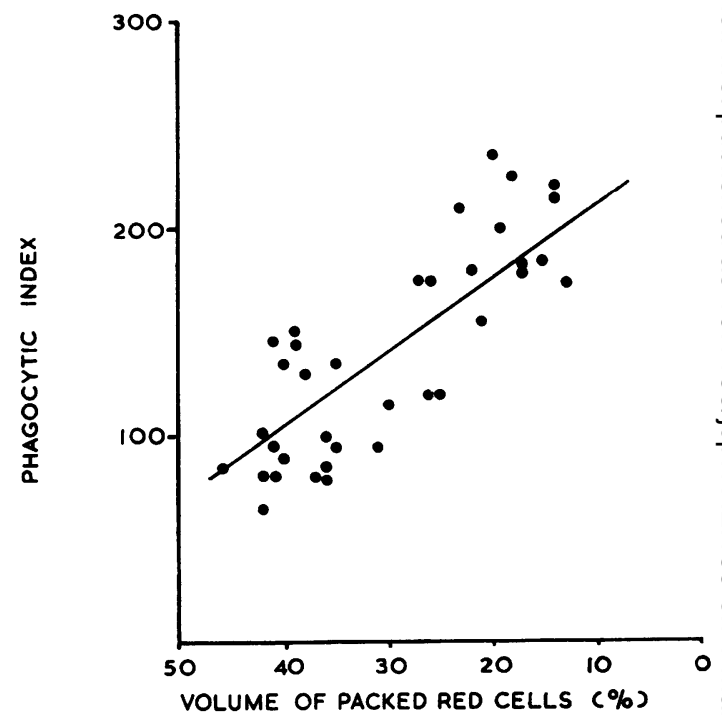

FIG. 2. The phagocytic index of normal whole blood related to changes in the volume of packed red cells result $-\vec{\theta}$ ing from the removal of red cells.

EXPERIMENT 3 The studies of Berry et al. (1945, 1947) were carried out with the incubating mixtures of cells and organisms continuously agitated. The procedures carried out in experiments 1 and 2 were therefore repeated with all the mixtures rotating inside the incubator at a speed of 1.3 to 1.7 revolu- $\overrightarrow{\overrightarrow{0}}$ tions per minute. In these conditions the mean 3 phagocytic index of 16 specimens of normal blood was $100 \cdot 1 \pm 15 \cdot 2$ and of 13 specimens of anaemic blood $140 \cdot 8 \pm 10 \cdot 8$. This is a significant differences $(\mathrm{p}=<0.03)$. The phagocytic index is related to the volume of packed red cells in a similar way to the results when the mixture is not rotated. Reduction of the volume of packed red cells in 16 specimens of normal venous blood resulted in an increase in theo phagocytic index.

EXPERIMENT 4 To observe whether the increase in phagocytic activity of neutrophils in anaemic blood is still apparent when the volume of packed red cells is reduced to a uniformly low level, venous blood samples were obtained from 30 normal subjects and 12 anaemic patients. The supernatant plasma was then removed with a pipette together with most of the leucocytes and as few of the red cells as possible ${ }_{+}^{+}$ The volume of packed red cells in the cell suspensions was $1-5 \%$ except in two cases where values of $6 \%$ and $8 \%$ respectively were obtained.

Although the absolute number of organism $\stackrel{\mathbb{\Omega}}{\Omega}$ ingested was greater than in whole blood, there was? no difference in activity between leucocytes from 
normal and anaemic blood. The mean normal phagocytic index was $100 \cdot 0 \pm 4 \cdot 1$ and the mean phagocytic index of 'anaemic' leucocytes was $100 \cdot 9 \pm 7 \cdot 5$. There was no relation between phagocytic activity and the volume of packed red cells when so few red cells were present.

The phagocytic index of neutrophils in whole blood is increased in cases of iron-deficiency anaemia and the increase is related to the reduction in the volume of packed red cells. A similar increase in the phagocytic index can be induced in normal blood by simple removal of red cells. There is no difference in phagocytic activity of neutrophil leucocytes from normal and anaemic blood when the red cells in each case are reduced to a uniformly low level.

\section{DISCUSSION}

Berry et al. (1945) showed that the phagocytic activity of neutrophils in anaemic blood is increased. They found that the magnitude of activity was roughly proportional to the severity of the anaemia and that phagocytosis decreased as the level of haemoglobin and red cells returned to normal after treatment. This was the case with both macrocytic hyperchromic and microcytic hypochromic anaemias. There appeared to be no correlation between phagocytosis and the type of aetiology of the anaemia being studied. The present investigation has confirmed these findings in the case of hypochromic iron-deficiency anaemia.

Fenn (1921) has shown that the rate of phagocytosis in a suspension depends on the number of collisions between phagocytes and particles. In normal whole blood the presence of large numbers of red cells may have the effect of interfering with contact between leucocytes and particles. The increase in phagocytosis in anaemic blood may be due simply to a reduction of this interference. The results of experiments 2 and 3 in this investigation suggest that this is the case. Phagocytic activity in normal blood was proportional to the lowering of the red cell volume when leucocyte and plasma concentration remained unchanged (Fig. 2).

Similar experiments performed by Berry et al. (1947) but involving dilution with saline, sometimes together with removal of red cells, gave variable results. In some cases there was increased phagocytosis when the blood was diluted, but this was interpreted as being due to differences in plasma concentration or to technical error. These workers concluded that the increased phagocytosis in anaemic blood was due neither to a reduction in red cells nor to changes in the plasma but to an intrinsic change in the leucocytes. This appeared to be supported by the finding of increased phagocytic activity in neutrophils isolated from anaemic blood compared with those from normal blood. These neutrophils were, however, obtained from oxalated blood and subjected to a considerable amount of manipulation. Mudd, McCutcheon, and Lucké (1934) have shown that phagocytosis is reduced by oxalate and it was found during the present investigation that mere standing at room temperature for $\mathbf{4 0}$ minutes without manipulation will impair phagocytic function.

When the red cell volumes of normal and anaemic blood are reduced to uniformly low levels, there is a high rate of phagocytosis in both cases but no difference between the two groups. This indicates that the activity of the leucocytes themselves is unchanged in iron-deficiency anaemia and is in keeping with the suggestion that differences found in samples of whole blood are entirely dependent on the volume of interfering red cells present.

This work was supported by a grant from the Board of Governors of the United Cardiff Hospitals.

\section{REFERENCES}

Berry, L. J., Davis, J., and Spies, T. D. (1945).J. Lab. clin. Med., 30, 910. Leyendecker R. M., and Spies, R. D. (1947). Blood, Special Issue No. 1, 98

Dacie, J. V. (1956). Practical Haematology, 2nd. ed. Churchill, London.

Fenn, W. O. (1921). J. gen. Physiol., 3, 439, 465, and 575.

Mudd, S., McCutcheon, M., and Lucké, B. (1934). Physiol. Rev., 14, 210. 